\title{
Correction to: Effect of design and operational parameters on nutrients and heavy metal removal in pilot floating treatment wetlands with Eichhornia crassipes treating polluted lake water
}

\author{
Mohamed S. Gaballah ${ }^{1,2}$ (D) Khiary Ismail ${ }^{3} \cdot$ Dominic Aboagye $^{2} \cdot$ Mona M. Ismail $^{1} \cdot$ Mostafa Sobhi $^{3} \cdot$ \\ Alexandros I. Stefanakis ${ }^{4}$
}

Published online: 5 February 2021

(C) Springer-Verlag GmbH Germany, part of Springer Nature 2021

\section{Correction to: Environmental Science and Pollution Research https://doi.org/10.1007/s11356-021-12442-7}

The title "Eichhornia Crassipes" should be "Eichhornia crassipes" as a scientific issue and the correct affiliation 1 is presented in this paper.

Publisher's note Springer Nature remains neutral with regard to jurisdictional claims in published maps and institutional affiliations.

The online version of the original article can be found at https://doi.org/ 10.1007/s11356-021-12442-7

\section{Mohamed S. Gaballah}

Saadga22@gmail.com

Alexandros I. Stefanakis

astefanakis@enveng.tuc.gr

1 National Institute of Oceanography and Fisheries, Cairo, Egypt

2 College of Engineering, Key Laboratory for Clean Renewable Energy Utilization Technology, Ministry of Agriculture, China Agricultural University, Beijing 100083, People's Republic of China

3 Agricultural and Bio-system Engineering Department, Faculty of Agriculture, Alexandria University, Alexandria, Egypt

4 School of Environmental Engineering, Technical University of Crete, 73100 Chania, Greece 